\title{
FUNCTIONAL ROLE OF STYLISTIC FIGURES: METAPHOR
}

\section{AND METONYMY}

\author{
Ol'viya Vysotska, \\ Lecturer of the Department of Foreign Languages for Humanities, \\ Ivan Franko National University of Lviv, \\ Lviv, Ukraine \\ e-mail: olviv@writeme.com
}

Received March, 10, 2019; Accepted May, 22, 2019

\begin{abstract}
The article deals with the word-forming role of stylistic figures (metaphors and metonymy) in the formation of polysemantic words-terms. The common regularities of the use of stylistic figures in various spheres of the humanities, ways of their change (semantic landslides), especially the semantic filling of terms in professional texts are revealed. It is noted that the semantic paradigm of metaphor is a complex system-forming unit that forms a set of derivatives motivated by the same sign. A metamorphic nominative function, capable of forming new concepts, is also traced. It is generalized that the metaphor is a semantic shift in meaning, and metonymy is a semantic shift in the reference. The stylistic figure of a metaphor performs both a figurative and an effective speech function and can be represented by a set of semantic markers or sems. The article argues that a stylistic figure, as a result of a combination of heterogeneous components of content that arose in the context, is singled out implicitly from it, realized both in the metaphor and in metonymy, providing a proper understanding of the speakers of the language. It is highlighted that metaphor is a semantic process, where the form of a linguistic unit is transferred from one referent to another based on the similarity of subjects / concepts in the mind of the speaker. The mechanism of the functioning of stylistic figures by the main regular models of the metaphorical semantic transition, which is a complicated multifaceted process of "generation" of new meanings, is shown. It is proved that penetrating into a professional language, the metaphor gradually loses its imagery, associativity and acquires a strict terminological meaning. It is argued that the semantic structure of the metaphor is formed in close interaction between the main and the auxiliary components, and the meaning that causes the metaphor is the structural component of the extensional meaning and determines the perception of the main subject of the metaphor. It is generalized that stylistic figures (metaphor, metonymy) are capable of creating new meanings in both semantic and cognitive dimensions, and their free combination enables the emergence of a new meaning that is actualized in a particular speech act.
\end{abstract}

Key words: stylistic figures, functional role of metaphor, semantic potential metaphor, generalized sign, semantic invariant, metonymy, categorical transition.

\section{Introduction}

The appearance and functioning of stylistic figures in professional terminology systems is predetermined primarily by social interests, between social relations, the unceasing advancement of scientific and technological progress. The urgency of the article is to clarify the intricacies of the essence of stylistic figures, their functional role in the generation of numerous meanings. The purpose of the article is to identify an abstract sign of a stylistic figure as a terminological 
combination of a professional language, which makes it possible to designate many objects and phenomena of the surrounding reality. The task is to identify the generalized features of stylistic figures, to analyse their semantic and functional peculiarities of their role in the formation of different meanings.

\section{Analysis of previous studies and publications}

Today in linguistics there is a widespread idea that there are links between the individual meanings of the word for similarity (metaphorical changes in meaning), and ties for spatial and temporal contiguity (metonymic changes), (A. Darmstöeter and others). In particular, in linguistic writings it is noted that the stylistic figure of a metaphor performs both a figurative and an effective speech function (V. Gak, R. Dudok, E. Paducheva, T. Podkolzina, etc.). That is, the change of semantics of a word, usually represented by a triad: metaphorical, metonymic, and functional "transition", where the common sign is a stable invariant in all cases of the use of the word - the term. Among the linguists, it is postulated that with the help of metaphor and metonymy polysemic terms are formed, where the initial universal meaning of the word can serve as the basis for each subsequent transference, and the terminology is already fixed. Thus, V. Leichyk states that "the cause of the emergence of ambiguity within the terminology system may be the "appropriation" of the urgent meaning, which has general features with the meaning of the term, which expresses other concepts" (Leichyk, 1987: 22).

In turn, R. Langacker believes that the starting point for the semantic analysis of the term is an integrated conceptualization, which can have any degree of internal complexity. It can be represented as a set of semantic markers or sems, where the cognitive domain, as such, is integrated with the conceptualization, rather than the totality of the family (Langacker, 1987: 48).

\section{Methods and methodology of research}

Methodological base and methods of research were formed on the basis of the analysis of scientific works of the Ukrainian and foreign researchers of the functional role of stylistic figures in the professional language. This served as a theoretical and methodological basis for interpreting the phenomenon of meaning in the structure of stylistic figures as a complex union of semantic components. The methodological principles of the meaning-sense method are used to differentiate the word-term on the diverse components of the invariant in language paradigma and variable meanings in speech syntagmatics. The description of the factual material also involves the analysis of dictionary definitions and the method of component analysis. The above mentioned meaning-sense method proves that the link between the basic and metaphorical values is the implicit component- the invariant found in the definition of the initial value, which performs an important semantic and functional role in the process of metaphorization. Therefore this mechanism is achieved by understanding the inner potential of the language. 


\section{Results and discussions}

In our opinion, the semantic potential of stylistic figures makes it possible to fill the "lacunae" in vocabulary articles. In particular, the metaphor and its variety "catachresis" < Catachresis from gr. - kata - against, chresthai - to use, under which we understand the use of the word in a new sense. That is, catachresis is the insertion of a new meaning to old words. However, if the catachresis is really due to the need, then the formed meaning quickly becomes a literal, in its metaphorical transference.

Thus, the functioning of the stylistic figure consists in updating the corresponding system of common associations (the system of related commonplaces), namely: let's say, if a person is a wolf, then it hunts the rest of the living creatures, the predatory (evil), constantly hungry, drawn into eternal struggle, etc. Such "virtual" judgements instantly appear in the mind of the subject and then are combined with the imagination of the main object, creating an unusual combination of meanings: (1) "a wolf in a sheep's clothing" - "a person who seems friendly, but, in fact, unpleasant and dangerous"; (2) "cry wolf” - "ask for help, which in reality is not necessary"; (3) "keep the wolf from the door" - "earn just enough to buy the most needed". It should be added that in the above-mentioned metaphorical phrases with "wolf" there is a distinction between common "trouble" and "negativity", which is the key to understanding their deep semantics.

As is well known, in addition to the nominative function of a metaphor, it also performs a conceptual function based on its ability to form new concepts based on pre-existing concepts. Conceptual metaphor is the creation of a new concept. Thus, $\mathrm{V}$. Gak argues that metaphor is a universal way of forming new language names based on existing ones (Gak, 1988: 14), that is, a metaphor is an example of dynamics in the field of lexical semantics. Since various objects are united by some new sign, adding on the basis of this sign to a class of concepts, it allows one's name to be used to denote another. Here we can generalize that metaphorization extends to the development of language, scientific and technological progress.

Consequently, we tend to believe that, through certain hierarchically organized operations, the human mind is capable of comparing those semantic concepts that are, to some extent, non-comparable. In our opinion, each word in an arsenal of numerous meanings combines a set of components or common features. Their free combination contributes to the emergence of new meaning. In the process of using some components of the meaning of the word, as secondary, are separated in the context, where from all possible components of the word in speech, only the meaning that is realized in a concrete communicative act remains. (Dudok, 2006: 198).

Thus, a stylistic figure, as a result of a combination of heterogeneous components of the content that arose in the context, is isolated from it implicitly, realized both in the metaphor and in metonymy, providing a proper understanding of the speakers of the language. For example, peril $(n)-(1)$ danger, risk; in peril of one's life - risking their lives. He commanded the army during a time of peril - He commanded the army at times of danger. (2) what is causing danger. - Icy roads are a peril to motorists - Slippery roads are dangerous for drivers. (3) At one's peril - at your own risk. - You ignore this warning at your peril - you ignore it at your own risk.

The factual material gives grounds to assert that the metaphor, metonymy expresses the opinion as clearly and precisely as the words in the primary meanings, 
which makes it possible to regard them as independent semantic components. In addition, we recall that the intuitive ideas of transfer value, Aristotle also articulated, believed metaphor to be a hidden comparison, which consists in transferring things of the name and belongs to something else. This was, apparently, the first definition of "metaphor" as a special term. So, in our understanding, a metaphor is a semantic process, where the form of the linguistic unit is transferred from one referent to another, based on the similarity of the objects / concepts in the minds of the speaker.

According to linguists, in particular, M. Johnson, J. Lacoff, the similarity of figurative comparison and metaphor is beyond doubt (Lakoff, 1981: 38). In the process of functioning of the metaphor it is manifested in the context as a new word, distinguishing in the subject some aspect that was not before, and therefore, there was no name. In our opinion, the fundamental difference between a metaphor and a semantic analogy lies in the fact that in the first case there is a transition of a linguistic sign from one semantic category to another, and in the other - the development of its meaning within the same category. In any case, the speaker does not fix, does not notice this "jump-like" semantic transition. Compare: "girl" "female child"; (2) "young unmarried woman"; (3) "female servant or employee"; (4) "informal sweetheart"; (5) "informal woman of any age, single or married", where the word "girl" does not necessarily refer to a young person of the female sex, but also refers to the unmarried woman of the elderly age. e. g. "A girl of sixty years", which, in its further development, became to mean "a woman of any age, both lonely and married".

It should be noted that in choosing a metaphor, the external role of objects, in which the common component is clearly traceable, plays a decisive role. That is, in the process of generalization of the concept, it also distinguishes between a differential feature that is relevant to a particular communication act. In addition to the external similarity of an object, an object of importance is the similarity of the function: "leg" - "leg of a man, table, bed" books with legs - books, which are not affiliated with stores; to have by the leg - put in a difficult position that has received further metaphorical development.

The variability of the word is manifested in the metaphor in cases where the phonetic shell of the word and its significance of the syllable are unchanged. In cases where the word does not lose its previous connection with denotat, we are dealing with a new metaphor. As soon as the "transition" of the name is fixed, then in the word next to the previous meaning there is a new one. In fact, we have the same word before us, but in another sense, and in this sense, we are talking about the metaphor as the "boundary" of the variation of the word for denotat (Paducheva, 1999: 26). The emergence of a new value of the syndicat immediately, figuratively speaking, "overgrown" with new features, creates a prototype of the future new concept: "the head of the family" - "a family head"; and "the head of a flower" - "a flower head", the head of the chapter - title, section; the head of the procession - the head of the procession, the columns; the head of the street - the beginning of the street; the head of the tone - introduction, introductory remarks, and more.

As we see, the differential sign of the "human head" was abstracted, generalized to use to distinguish other concepts such as "human head" and the metaphors "the head of a mountain (page)" - "the upper part of the mountain (page)", which are formed on the same sign "surface", "importance", and form its semantic invariant. 
According to our belief, the metaphor and its variety is one of the main means for the development of any lexical corps, where the metaphor's semantic function is realized in various dimensions. According to the researchers, the main ones belong to: (1) from nature to the inner world of a man, (2) from the human body to its spiritual qualities, (3) from one phenomenon of nature to another, etc. (Petrov, 1990: 121). Let's return to the analysis of metaphor as the main semantic function of language. In all metaphorical changes, the sign of the original concept is unchanged: so in the word "nest" - (1) "nest", "bird housing" or "human community"; (2) "hole in a board at the bottom of the boat, where the bottom of the mast is installed"; (3) "hollow in a car where the axles or rods are installed"; (4) "selection of words from one root". Next in the context-based format, nest-egg-actualized a functional role-money delayed for a black day or for a specific purpose such as: It was never intended for anything but a mere nest-egg for the future (M.Twain).

Consequently, the concepts described by the word "nest" - "nests" are very different; if the pit for the mast can be identified with the "hole" in the car, then the "house of the bird", "human community", "picking single-root words", and the deferred money here does not fit. However, the common invariant sign "receptacle" that covers and unites all of the aforementioned objects and things (eggs, birds, relatives, words, and money) is kept in all cases as communicatively relevant as a common semantic rod. We share the opinion of the researchers that: (1) the meaning of the metaphor can be considered based on logical analysis; (2) metaphors form groups on the principle of "parallel inclusion", that is, each subsequent value tends to the main invariant as its stable component (Podkolzina, 1994: 73).

We tend to believe that the metaphorical process of creating meanings affects both the imagination of a man and the development of a society. However, according to the similarity of the form, let us quote: quill stands for a porcupine, a toothpick, and a float rod (rods); and (those) sleeve; (mues) cane box and the like. Here it should be added that the "transfer" of the function has much in common with the metaphor, since it is based on the similarity of signs, where things such concepts can be different, but they are united by a function commonality. For example, "quill" - "goose feather" passed its name to a steel feather, because in them the common function is "a tool for writing". From here we obtain the metaphorical imagery of the phrase: to draw one's quill against sb/sth. - To speak in the press against someone, something.

The given factual material confirms that the metaphor does not have semantic constraints; it can explicate any meaning while maintaining a common invariant trait. At the same time, we associate a metaphor with a particular subject that supports it within the meanings directly or indirectly related to reality.

In the process of studying the mechanism of the functioning of stylistic figures, we isolate the main regular models of the metaphorical semantic transition, which, as a complex multifaceted process of "generation" of new meanings, leads to a complete "rearrangement" of the semantic structure of the word (Alekseeva, 1996: 57). According to our observations, the noun is characterized by the highest versatile metaphorical productivity: let's say the word-term "bridge" - "bridge" in computer technology contains a metaphorical change in meaning, which is based on the similarity of the functions of two objects and causes us to associate with a road bridge, which also performs the "connection" function: "bridge across a waterway"; and "bridge - the gap in understanding between different cultures" - 
in which the generalized component is "anything resembling a bridge in shape and function", all that in shape and function resembles a bridge in medicine, technology, optics, social relations, etc.

Thus, the semantic paradigm of metaphor is a complex system-forming unit that forms a set of derivatives, motivated by the same nominative "bridge" in different phrases: a gold / a silver bridge - a way for honorary retreat; to throw sb over the bridge - Bring someone up, give someone a foot.

In order to understand the mechanism of "generation" of metaphorical meaning, one must imagine that a metaphor is a certain collection of meanings that denotes the class of objects, phenomena, actions on the general sign of the nomination of another, similar to this class of objects or individuals. In this sense, U. Weinreich rightly argues that with the help of a metaphor, one can express an opinion as precisely as in other words. Therefore, there is a metaphor that there is no other word that could express its meaning (Weinreich, 1963). In the process of knowing the objects of the world, first we compare them, we find similarity between them, and in order to consolidate our knowledge, we give the new object an already known name, therefore, the metaphor does not arise in the context as a completely new word, it actualizes a number of those features which correspond to a specific speech act.

The analysis of the sample base convincingly shows that the vocabulary used to describe a person, the structure of his body, the names of parts of the human and animal body, is especially easy and often used to call special terms in the metaphorical sense. Here, the most numerous group of words is formed on the basis of a metaphorical transposition based on similarity and function, such as: mouth $(n)$ - mouth and mouth of the river (1) external orifice in head; (2) the outfall of the river, the mouth of the river (= where it joins the sea); the mouth of a cave. It is obvious that the community, the unity of the word-term is due to the semantic center or the semantic core: the "mouth that resembles a mouth", rivers, caves, etc., which, in the function of a generalized sign, is actualized in the following metaphorical phrases: to make smb's mouth water - to urge someone's appetite; to put words into smb's mouth - to prompt someone.

Thus, in the process of metaphorization, we get more and more new meanings, where the metaphor in the language creates names that are capable of identifying existing objects: "nose": (1) "part of the human face" - "nose", "part of the face of a man"; (2) "corresponding part of the head in other animals" means "the corresponding part of the head of other animals"; (3) "sense of smell" - "a sense of smell”; (4) "prominent or projecting part of sth". "As a ship or airplane" "the front part of something (ship, aircraft, etc.)"; (5) "ability to perceive or detect": a reporter with a nose for news - "ability to receive information" (about journalists); (6) "informal means considered interference or meddling" - "nose" as a means of interference in a case"; e.g. "Keep your nose out of this" - "do not interfere with this."

The above examples clearly show that the metaphorically termed expression "calls" the new denotat in the name of a commonly used well-known phenomenon, since both have the same generalized sign. It is, therefore, logical that the term acquires a new meaning through its immanent meaning, where penetrating into a professional language, the metaphor gradually loses its imagery, associativity, and acquires a strict terminological meaning (Teliya, 1988: 143). 
We can generalize our judgements that in metaphorical terms, there is a knowledge of the designated object and a set of semantic features. So, for example, a brave man is called "lion" - brave, strong, etc., because in the mind of a man it was identified with a lion. Since "lion" has various objective attributes among which there is "courage" - human consciousness abstracted "courage" precisely with this quality. So, on the basis of the sem "courage", a new concept emerges, which makes it possible to use the word "lion" in relation to a person.

We are inclined to believe that in the process of analysis of the metaphor it is important to identify the patterns of transposition of the meanings of concepts from one sphere to another, which is reflected in the changes in the meaning of wordterms. The above-mentioned animal's name "lion" for humans, which, of course, denotes the appearance of the character, such as "horse", "bear", "donkey", etc. "horse", "bear", "donkey", etc., can also be used in the field of material objects or related mechanisms (crane, dog, goat, etc.) in the following metaphorical terms: Lion is a brave and strong man; as bold as a lion - brave like a lion. Horse - frame, stand. Bear - an uneducated, rude person; - to behave like a bear; be awkward. Donkey is a fool, and so on.

We can assert that the semantic structure of the metaphor is formed in close interaction between the main and the auxiliary components. The sign of the meaning that causes the metaphor is the structural component of the extensional meaning and determines the perception of the main subject of the metaphor. As a result of the interaction of the two components, the main and the secondary, an intensive metaphor is formed, its new concept, which cannot be expressed by others, not metaphorically.

Another type of stylistic trail - metonymy (<gr. - metonimia - renaming) - a stylistic figure, which denotes a semantic process, where the form of the linguistic unit "passes" from one referent to another on the basis of one or another related feature. This is a universal means by which the name of one thing is replaced by another, having close semantic ties among themselves. The simplest case of metonymy is the correlation, under which we mean part of the whole (pars pro toto) or vice versa - (Synecdoche) - (<gr. - 110ynecdoche - get together). In metonymy and its kind of synecdoche, the displacement of the name between speeches is associated with the actual adjacency of physical contact or contact in different attitudes, for example, "a fleet of fifty sails" - a fleet of fifty sail boats.

Thus, metonymy in its classification may include the specialization, the specification of the lexical value, and generalization, that is, the "transition" to the corresponding generalized value. Similar metonymic categorization and, as a consequence, desmenation of the lexical meaning leads to the fact that it, so to say, "exaggerates" its own limits, its form constantly becomes an expression of the corresponding categorical meaning. Let's compare the interpretation of a number of phenomena as semantic "transitions" from one part to the whole and, conversely, in the action plan of synecdoche as a metonymic transposition, where a part is replaced by an integer or an integral part: "many mouths (people) to feed" - "feed a lot of "mouths" (in the sense of people), or "starting a car (the car's engine)" - "to start a car (in the sense of its engine)".

In our view, the difference between metonymy and metaphor can be interpreted as a difference in the "horizontal" and "vertical" plans of semantic processes, where metonymy occurs between different categorical values, whereas 
the metaphor is only within the same value. As an example of the main wordformation level of general categorical meanings, let's look at a metonymic transition between such values as an object, or its effect, for example: "a mother" - "(to) mother (a child)" - "to be a mother (child)".

At the level of lexical, individual values, this categorical transition can be complicated by the implicit comparison, that is, metaphorization, which enables a person to create a similarity between very different individuals and classes of objects, because there is nothing more fundamental to thinking in the language, believes U. Quine - than our sense of similarity (Quine, 1977: 157). We share the opinion that such a feeling - a common stimulus for the formation and metonymy, and metaphors, giving the semantic process of thought creation. The actual speech situation can be deployed in two cognitive ways: the same sign can pass into another context, either by similarity or adjacency, that is, on the axis of the metaphor and on the axis of metonymy, because, as R. Uetli states, the metaphor is a word which replaces another "word", because of the similarity or analogy between what they denote (Whately, 1846: 280).

\section{Conclusions}

Consequently, from the above, we arrive at the conclusion that metaphor and metonymy, while in syntagmatic terms, identify an integer (metonymy) and semantic deployment (metaphor). Given that the metaphor represents the vertical axis in the semantic processes of word formation, it ensures semantic deployment, the metaphor in quantitative terms dominates metonymy. Therefore, the metaphor is, first and foremost, a semantic shift in meaning, and metonymy is a semantic shift in the reference. Thus, stylistic figures (metaphor, metonymy) are capable of creating new meanings in both semantic and functional dimensions. Their free combination enables the emergence of a new meaning, which is actualized in a concrete communicative act. Thus, stylistic figures, as a result of a combination of heterogeneous components that have arisen in the context and separated from it implicitly, provide a proper understanding of the commune of the cants. The problem of the functioning of stylistic figures in order to create new terminological meanings in a professional discourse requires in-depth analysis of it, not only at the semantic and functional level, but also in the cognitive and conceptual planes.

\section{References}

Alekseeva, Larisa M. 1996. The metaphorical nature of the term. Perm.

Gak, Vladimir. 1988. "Metaphor: universal and specific." Metaphors in language and text. Moscow 11-26.

Dudok, Roman I. 2006. Stylistic figures and their semantic function. Kharkiv:

V. N. Karazin Kharkiv National University.

Lakoff, George. 1981. "On generative semantics.” New in foreign linguistics.

Leichyk, Volodymur M. 1987. "The term and its definition." Terminology and Terminography in Indo-European languages 135-145. Vladivostok. 
Paducheva, Elena V. 1999. "Methonimic and Methaphoric Transitions in the Verb Paradygm "to assign." The Kibric A. B $60^{\text {th }}$ anniversary. Moskwa.

Petrov, V.V. 1990. "Metaphor: from semantic representations to cognitive analysis." Questions of linguistics 3: 439.

Podkolzina, T. A. 1994. Metaphor and paradox in English terminology. $\mathrm{PhD}$ diss. Moskwa.

Teliya, Veronika N. 1988. "Metaphor as a model of semantic production and its expressive and evaluative function." In Metaphor in language and text. Moskwa. Paris.

Darmesteter, Arsène. 1899. La vie des mots etudiee dans leurs significations.

Langacker, Ronald N. 1987. "A View of Linguistic Semantics.” Foundation of Cognitive Grammar 1: 48-95. Stanford: Stanfors University Press.

Whately, Richard. 1846. Elements of Rhetoric. London.

Quine, Willard Orman. 1977. "Natural Kinds." In Naming, necessity and natural kinds. London.

Weinreich, Uriel. 1963. Lexicographic definition in descriptive semantics. 